\title{
Thermal stability of silicon surface passivation by APCVD $\mathrm{Al}_{2} \mathrm{O}_{3}$
}

\author{
Lachlan E. Black ${ }^{\mathrm{a}, *}$, Thomas Allen ${ }^{\mathrm{a}}$, Andres Cuevas ${ }^{\mathrm{a}}$, Keith R. McIntosh ${ }^{\mathrm{b}}$, Boris Veith ${ }^{\mathrm{c}}$, \\ Jan Schmidt ${ }^{\mathrm{C}}$ \\ a Research School of Engineering, The Australian National University, Canberra, ACT 0200, Australia \\ ${ }^{\mathrm{b}}$ PV Lighthouse, Coledale, NSW 2515, Australia \\ ${ }^{\mathrm{c}}$ Institute for Solar Energy Research Hamelin (ISFH), Am Ohrberg 1, 31860 Emmerthal, Germany
}

\section{A R T I C L E I N F O}

Keywords:

Surface passivation

$\mathrm{Al}_{2} \mathrm{O}_{3}$

Solar cells

Silicon

\begin{abstract}
A B S T R A C T
We investigate the thermal stability of silicon surface passivation provided by aluminium oxide $\left(\mathrm{Al}_{2} \mathrm{O}_{3}\right)$ films deposited using atmospheric pressure chemical vapour deposition (APCVD) and fired in a belt furnace at a peak temperature of $\sim 810{ }^{\circ} \mathrm{C}$. Firing stability is investigated for $p$ - and $n$-type substrates as a function of $\mathrm{Al}_{2} \mathrm{O}_{3}$ film thickness both with and without a plasma-enhanced chemical vapour deposition (PECVD) $\mathrm{SiN}_{x}$ capping layer, and for boron-diffused surfaces with a $\sim 10 \mathrm{~nm} \mathrm{Al}_{2} \mathrm{O}_{3}$ film only. Excellent thermal stability of the passivation is demonstrated, with effective carrier lifetimes in $n$-type silicon wafers remaining stable or even improving after firing, and lifetimes in $p$-type wafers initially degrading slightly but recovering to above their initial values following $\sim 10 \mathrm{~min}$ illumination by a halogen lamp at $\sim 20 \mathrm{~mW} / \mathrm{cm}^{2}$. Film thickness appears to be unimportant to stability, as does the presence of the capping layer. Surface recombination velocities of less than $3 \mathrm{~cm} / \mathrm{s}$ for $1.35 \Omega \mathrm{cm} p$-type and less than $2 \mathrm{~cm} / \mathrm{s}$ for $1.2 \Omega \mathrm{cm} n$-type substrates are measured after firing and illumination. The passivation of boron-diffused surfaces is also shown to improve slightly following firing, with a post-firing saturation current density of $42 \mathrm{fA} / \mathrm{cm}^{2}$ on a diffusion with a sheet resistance of $100 \Omega / \square$ and surface dopant concentration of $\sim 1.3 \times 10^{19} \mathrm{~cm}^{-3}$. Capacitance-voltage $(C-V)$ measurements show that short firing times result in an initial reduction of the interface defect density $D_{i t}$ and a slight increase of the negative insulator fixed charge density $Q_{f}$, while longer firing results in a substantial increase in both $Q_{f}$ and $D_{i t}$.
\end{abstract}

(c) 2013 Elsevier B.V. All rights reserved.

\section{Introduction}

Aluminium oxide $\left(\mathrm{Al}_{2} \mathrm{O}_{3}\right)$ is currently the material of choice to provide surface passivation for the next generation of high efficiency silicon solar cells. Thin films of $\mathrm{Al}_{2} \mathrm{O}_{3}$ have been shown to exhibit exceptional passivation properties, particularly on $p$-type silicon surfaces, thanks to a large negative insulator fixed charge density combined with a low interface defect density. While initial work was mostly based on atomic layer deposition (ALD) [1,2], deposition of such highly-passivating films has since been demonstrated via several high-throughput techniques, including spatial ALD [3,4], plasma-enhanced chemical vapour deposition (PECVD) [5,6], atmospheric pressure chemical vapour deposition (APCVD) $[7,8]$, and reactive sputtering $[9,10]$.

While $\mathrm{Al}_{2} \mathrm{O}_{3}$ has been demonstrated to provide excellent passivation of crystalline silicon surfaces, process integration remains an important issue. In particular, compatibility with the

\footnotetext{
* Corresponding author at:. Research School of Engineering, The Australian National University, Canberra, ACT 0200, Australia. Tel.: +612 61255132.

E-mail address: lachlan.black@anu.edu.au (L.E. Black).
}

high temperature contact-firing step used in industry-standard screen-printed metallisation has been identified as a potential concern. Several authors have reported that the surface passivation provided by both plasma-assisted and thermal ALD $\mathrm{Al}_{2} \mathrm{O}_{3}$ degrades substantially following a firing step [11-14], and that this degradation can be mitigated by the addition of a PECVD $\operatorname{SiN}_{x}$ capping layer [12-14]. Conversely, it has been reported by others that plasma-assisted ALD (PA-ALD) $\mathrm{Al}_{2} \mathrm{O}_{3}$ films are relatively firing-stable and their passivation suffers only minor degradation, and that a $\operatorname{SiN}_{x}$ capping layer has no effect on stability $[15,16]$. It appears that, as with other film characteristics, the deposition method and conditions may exert a significant influence on the thermal stability of the passivation.

In this contribution we investigate the firing stability of $\mathrm{Al}_{2} \mathrm{O}_{3}$ deposited by APCVD. This technique is interesting for industrial application of $\mathrm{Al}_{2} \mathrm{O}_{3}$ passivation because of its relative simplicity compared to other high-throughput deposition techniques. Both $p$ - and $n$-type silicon substrates are considered, as well as borondiffused planar surfaces, and we examine the influence of film thickness and a $\operatorname{SiN}_{x}$ capping layer. Capacitance-voltage measurements are used to separate changes in charge-assisted and chemical surface passivation. 
Several authors have reported significant blistering of $\mathrm{Al}_{2} \mathrm{O}_{3}$ or $\mathrm{Al}_{2} \mathrm{O}_{3} / \mathrm{SiN}_{x}$ stacks during high-temperature processing, particularly for thicker layers [17-20]. However, no conclusive correlation between visible blistering and changes in surface passivation has been reported. In this work we are concerned primarily with changes in surface passivation, and therefore we do not examine blistering in detail.

\section{Experimental method}

Symmetrical lifetime structures were prepared on $1.35 \Omega \mathrm{cm}$ p-type and $1.2 \Omega \mathrm{cm} n$-type, $\langle 100\rangle, 300 \mu \mathrm{m}$ thick, $5 \mathrm{in}$. semi-square FZ Si wafers, and on boron-diffused $100 \Omega \mathrm{cm}$ p-type, $\langle 100\rangle$, $435 \mu \mathrm{m}$ thick, $4 \mathrm{in}$. FZ Si wafers. The latter received an $\mathrm{HF}: \mathrm{HNO}_{3}$ damage etch, while the former were electrochemically polished by the manufacturer. All received an RCA clean, with a final HF dip and DI water rinse performed immediately prior to $\mathrm{Al}_{2} \mathrm{O}_{3}$ deposition. Boron diffusions were performed in a quartz tube furnace at 900,950 , and $1000{ }^{\circ} \mathrm{C}$ from a liquid $\mathrm{BBr}_{3}$ source, with sheet resistance measured by four-point probe prior to film deposition. The electrically active dopant profiles were measured by the electrochemical capacitance-voltage (ECV) method once processing and characterisation of the samples was complete. Metalinsulator-semiconductor (MIS) structures for capacitance-voltage measurements were prepared on $1 \Omega \mathrm{cm} p$-type, $\langle 100\rangle, 480 \mu \mathrm{m}$ thick, 4 in. FZ Si wafers. These received an $\mathrm{HF}: \mathrm{HNO}_{3}$ damage etch prior to the RCA clean and HF dip. Additional symmetrical lifetime structures were prepared on the same substrates for comparison. The MIS structures were contacted ohmically at the rear with GaIn paste, with gate contacts formed by thermal evaporation of Al dots $(\varnothing \approx 700 \mu \mathrm{m})$. Metallisation occurred after firing.

The $\mathrm{Al}_{2} \mathrm{O}_{3}$ films were deposited using an inline APCVD belt furnace system (Schmid Thermal Systems [21]) from triethyldialuminium-tri-(sec-butoxide) (TEDA-TSB) and water vapour at a substrate temperature of $\sim 440{ }^{\circ} \mathrm{C}$. An initial layer of $\sim 10 \mathrm{~nm}$ was deposited for all samples in order to ensure identical initial interface properties. Some samples subsequently received a second deposition of either 20 or $100 \mathrm{~nm}$, resulting in total $\mathrm{Al}_{2} \mathrm{O}_{3}$ film thicknesses of $\sim 10,30$ and $110 \mathrm{~nm}$. This second deposition was performed at a lower belt speed and set-point temperature in order to produce a thicker film with a similar deposition temperature profile. The samples did not receive a separate post-deposition anneal. Some samples additionally received a $100 \mathrm{~nm}$ thick capping layer of PECVD $\mathrm{SiN}_{x}$ (Roth \& Rau SiNA) with a refractive index $n=2.05$ at $632 \mathrm{~nm}$. The same film has previously been shown to improve firing stability when used as a capping layer for $\mathrm{ALD} \mathrm{Al}_{2} \mathrm{O}_{3}$ films [14]. The $5 \mathrm{in}$. semi-square wafers were divided into $4 \times 4 \mathrm{~cm}^{2}$ pieces for lifetime measurements and firing, while the 4 in. undiffused wafers were quartered.

Firing was performed in an industrial infrared conveyor-belt furnace (Centrotherm Contact Firing Furnace DO-FF-8.600-300). A firing profile with a peak set-point temperature of $910{ }^{\circ} \mathrm{C}$ and belt speed of $5.9 \mathrm{~m} / \mathrm{min}$ was used for most of the samples. In a few cases a slower profile with a peak set-point of $860^{\circ} \mathrm{C}$ and a belt speed of $3 \mathrm{~m} / \mathrm{s}$ was used instead. These profiles represent typical firing profiles used in the production of screen-printed solar cells, and are respectively the same as the "fast" and "slow" profiles used in [14]. Both profiles result in a similar peak wafer temperature of $\sim 810^{\circ} \mathrm{C}$, with $\sim 6$ and $12 \mathrm{~s}$ above $600{ }^{\circ} \mathrm{C}$.

The effective excess carrier lifetime $\tau_{\text {eff }}$ as a function of the excess carrier concentration $\Delta n$ was measured using the photoconductance decay method using a Sinton WCT-120 lifetime tester. The lifetime was measured before and after firing, and again after illumination with a halogen lamp at $\sim 20 \mathrm{~mW} / \mathrm{cm}^{2}$ for approximately $10 \mathrm{~min}$. The upper limit of the surface recombination velocity
$S_{\text {eff,UL }}$ was calculated from $\tau_{\text {eff }}$ according to

$S_{\text {eff }, U L}=\frac{W}{2}\left(\frac{1}{\tau_{e f f}}-\frac{1}{\tau_{\text {bulk,intrinsic }}}\right)$

where $W$ is the wafer thickness, and $\tau_{\text {bulk,intrinsic }}$ is the intrinsic bulk lifetime, determined using the empirical parameterisation of [22]. Measurements of the saturation current density $J_{O E}$ of the borondiffused samples were performed under quasi-steady-state illumination using the generalised photoconductance analysis. The optical constant was determined from spectral reflectance and transmission measurements of the samples combined with knowledge of the flash spectrum and external quantum efficiency of the reference cell, in the manner of [23]. $J_{O E}$ was extracted from the measured $\tau_{\text {eff }}$ via the expression

$J_{0 E}=\frac{q W n_{i}^{2}}{2} \frac{d}{d \Delta n}\left(\frac{1}{\tau_{e f f}}-\frac{1}{\tau_{\text {bulk,intrinsic }}}\right)$

where $q$ is the fundamental charge, and $n_{i}$ is the intrinsic carrier concentration in silicon, calculated using the expression of [24] at $300 \mathrm{~K}$. The value of the derivative in (2) was calculated locally using a quadratic fit over five data points, and averaged over the range where it showed the least variation with $\Delta n$, which was generally for $\Delta n$ between 1 and $2 \times 10^{16} \mathrm{~cm}^{-3}$.

Quasi-static and high-frequency $(1 \mathrm{MHz})$ capacitance-voltage $(C-V)$ measurements were performed using an HP 4284A precision LCR metre, and HP 4140B picoammeter/dc voltage source. The sample was held on a temperature-controlled chuck at $25^{\circ} \mathrm{C}$. The high frequency capacitance was corrected for parasitic series resistance and inductance, and dielectric dispersion, while the quasi-static capacitance was corrected for leakage current and zero offsets in the metre via measurements at two different sweep rates. Gate areas were measured by optical microscopy. The insulator capacitance was calculated by the method of [25]. Doping was calculated from the high-frequency capacitance in depletion, after correction for interface trap stretchout [26], while the flatband voltage was calculated from the offset between this corrected depletion capacitance and the ideal value [26]. An iterative procedure was used to determine all parameters selfconsistently. The insulator fixed charge density $Q_{f}$ was calculated under the assumption that $Q_{f}$ was entirely located at the $\mathrm{Si}-\mathrm{Al}_{2} \mathrm{O}_{3}$ interface, while the interface defect density $D_{i t}(E)$ as a function of energy in the bandgap $E$ was determined from the quasi-static capacitance using the method of [27].

\section{Results and discussion}

\subsection{Firing stability}

Fig. 1 shows lifetime as-deposited, after firing (with the "fast" profile), and after firing and illumination, for $p$ - and $n$-type samples with various thicknesses of $\mathrm{Al}_{2} \mathrm{O}_{3}$, with and without a $\mathrm{SiN}_{x}$ capping layer. Lifetimes of $p$-type samples generally dropped significantly after firing, but recovered above their initial values after a short period of illumination, as discussed below. Conversely, lifetimes of $n$-type samples sometimes fell, but often increased after firing, and usually fell very slightly after illumination. Fig. 2 shows the injection dependence of the lifetime at each stage for several representative samples. In principle, the negative charge of $\mathrm{Al}_{2} \mathrm{O}_{3}$ could be expected to result in surface recombination velocities that are independent of the excess carrier concentration in low injection for $p$-type substrates, but strongly injection-dependent for $n$-type substrates [28]. However other recombination mechanisms and measurement artefacts may also influence the effective lifetime. The significant dip in the lifetime of the p-type samples in low injection is likely due to bulk Shockley-Read-Hall recombination, while the apparent lack of 
a

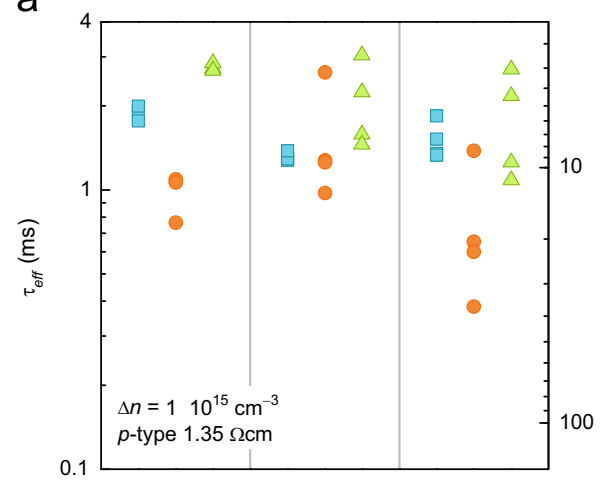

C

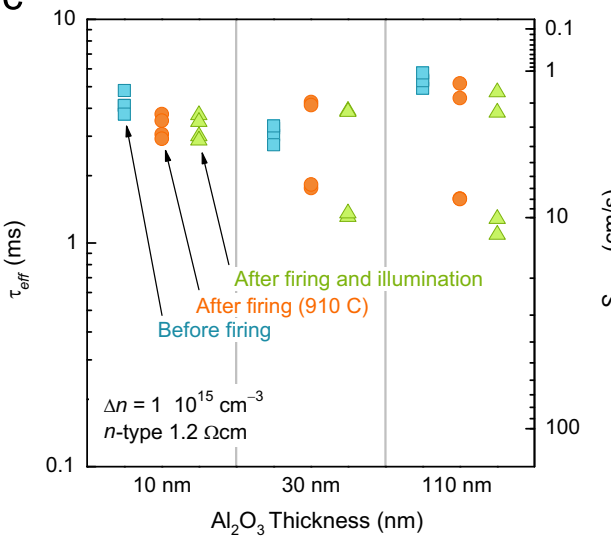

b

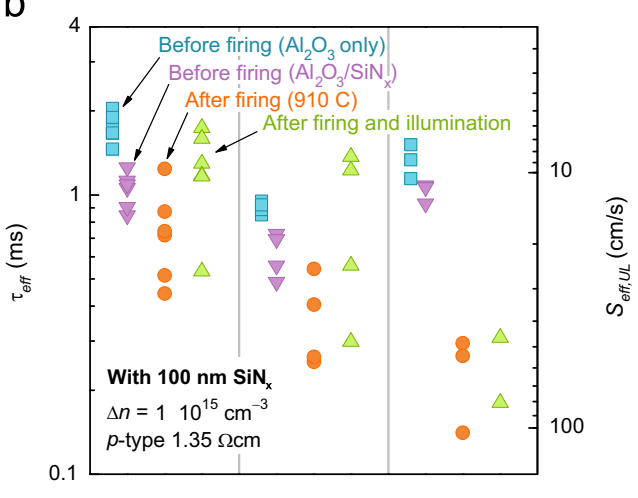

d

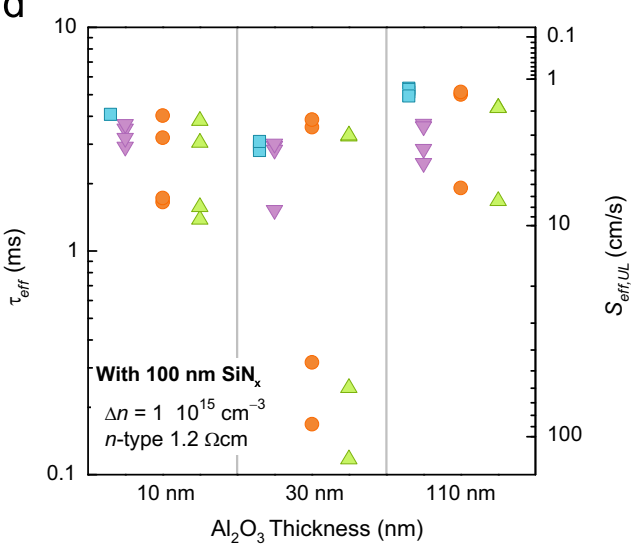

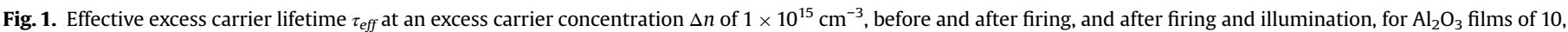

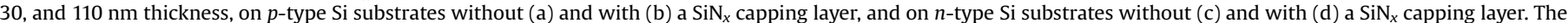
upper limit of surface recombination velocity $S_{\text {eff,UL }}$ calculated from (1) is also shown.

an injection dependence in the lifetimes of the $n$-type samples is probably due to a depletion region modulation effect. Both dependencies are also observed for the same type of substrates passivated with PA-ALD $\mathrm{Al}_{2} \mathrm{O}_{3}$ layers [28].

\subsection{Effect of $\mathrm{Al}_{2} \mathrm{O}_{3}$ film thickness and $\mathrm{SiN}_{x}$ capping layer}

Although there was some amount of sample-to-sample variation in lifetime due to differences in film deposition conditions and handling damage, there appears to be little systematic influence of the $\mathrm{Al}_{2} \mathrm{O}_{3}$ film thickness on the thermal stability of the passivation. Indeed it is notable that even for samples that were known to have suffered significant handling damage before firing, the firing step actually tended to reduce or eliminate the lifetime disparity with other samples (data not shown). There are two notable exceptions to this generally observed thickness independence: (i) the slightly lower initial lifetimes for the $30 \mathrm{~nm} \mathrm{Al} \mathrm{Al}_{3}$ films of Fig. 1(b-d), which are reflected in lower post-firing lifetimes at least in the case of the $p$-type sample (Fig. 1(b)), are believed to be a result of the fact that these samples had their initial films stripped and re-deposited due to problems with the initial deposition; (ii) the very low post-firing lifetime of the $p$-type sample with $110 \mathrm{~nm}$ thick $\mathrm{SiN}_{x}$-capped film in Fig. 1(b) was observed to be correlated with significant blistering, which was minimal or non-existent on the other samples.

The addition of a $\mathrm{SiN}_{x}$ capping layer resulted in an initial reduction of lifetime for all samples, although the lifetime remained high. Firing stability appeared to be unaffected by the presence of the capping layer, with the $\mathrm{SiN}_{x}$-capped samples exhibiting similar relative lifetime changes upon firing and illumination to those with single $\mathrm{Al}_{2} \mathrm{O}_{3}$ layers. Overall, the $\mathrm{SiN}_{x}$ capping layer neither helped nor significantly hindered the thermal stability of the $\mathrm{Al}_{2} \mathrm{O}_{3}$ passivation.

\subsection{Effect of post-firing illumination}

As noted above, it was found that for the $p$-type samples of Fig. 1, a short period of illumination resulted in a dramatic recovery of the post-firing lifetime to values above even the as-deposited values. Conversely, in $n$-type samples, post-firing illumination tended to reduce the lifetime very slightly from post-firing levels. This lifetime recovery effect for $p$-type samples under illumination has been reported previously for PA-ALD $\mathrm{Al}_{2} \mathrm{O}_{3}$ films on the same substrates after firing [14]. A similar effect with the same trends for $p$ - and $n$-type samples has also been reported for $\mathrm{SiO}_{x} / \mathrm{SiN}_{x}$ stacks [29]. It is clear that the effect is not related to bulk contamination by iron [30], because the lifetime increase occurs more or less uniformly across the whole injection range (Fig. 2). However, as noted below, the effect was not observed for samples prepared on other $p$-type substrates, both diffused and undiffused, so that we cannot rule out some influence of the substrate. Samples stored in the dark and remeasured five months after the initial firing and illumination showed lifetimes that had fallen by only $20-30 \%$ of the difference between pre- and postillumination values, indicating that the time constants involved in lifetime decay after illumination are much longer than those of the initial improvement. No significant change in lifetime under illumination was observed for the samples prior to firing.

Presuming that the effect represents a real change in the surface passivation, we should note that the level of illumination used is less than that to which cells would be exposed in the field, and illumination on a single side appears to be sufficient to activate the recovery on both sides of the sample, so that even 
a

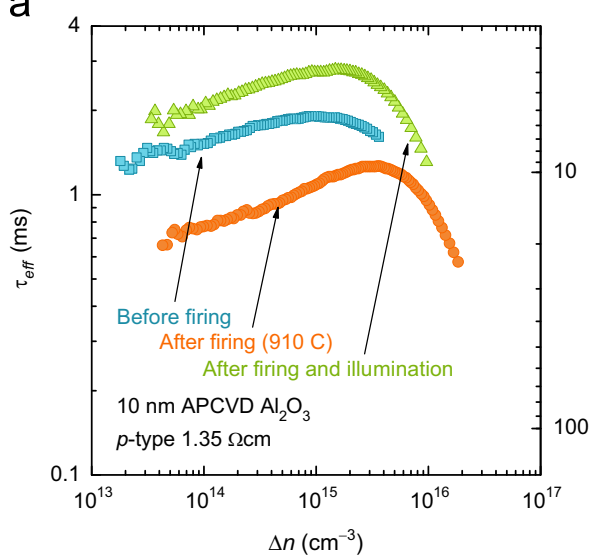

C

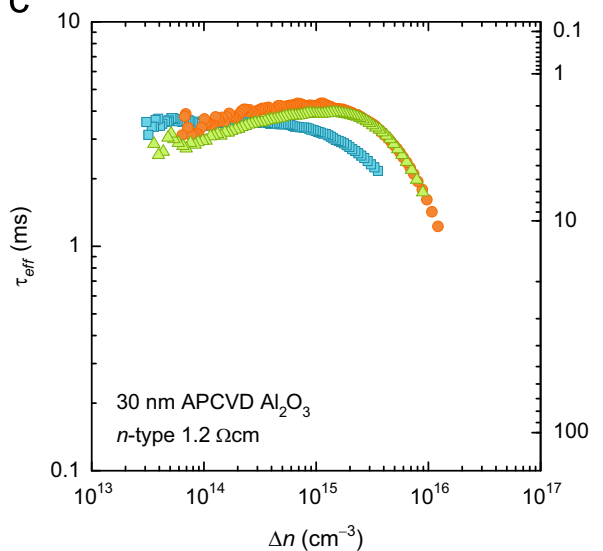

b

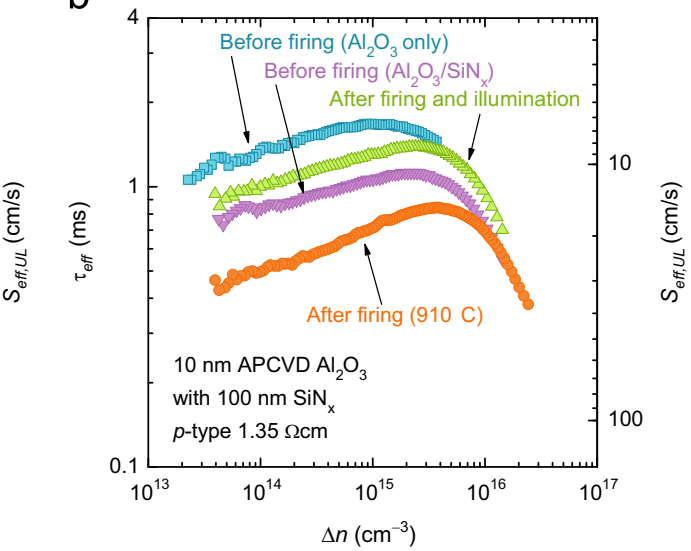

d

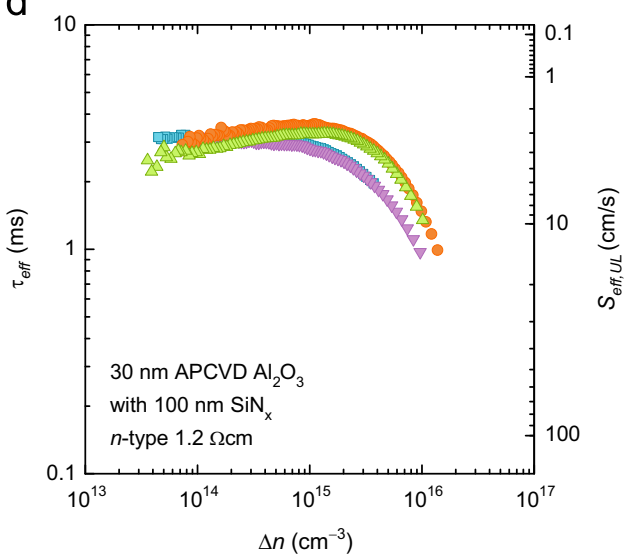

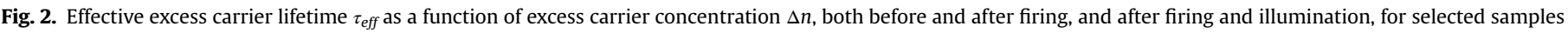
from Fig. 1.

rear-side $\mathrm{Al}_{2} \mathrm{O}_{3}$ passivation would likely be fully restored by illumination during device operation, without the need for additional processing steps. This indicates that the recovery is related to the increased carrier concentration under illumination, and not to the energy of the incident photons, since high energy photons will only be absorbed close to the illuminated surface.

\subsection{Boron diffused surfaces}

The passivation provided by the $\mathrm{Al}_{2} \mathrm{O}_{3}$ films on planar borondiffused surfaces was also found to be firing stable. Fig. 3 shows the measured $J_{O E}$ as a function of sheet resistance for the borondiffused samples passivated with $\sim 10 \mathrm{~nm}$ of $\mathrm{Al}_{2} \mathrm{O}_{3}$, both asdeposited, after firing with the "fast" profile, and after post-firing illumination. The inset shows the electrically active dopant profiles of the three diffusions, as measured by ECV. Fig. 4 graphically shows the $J_{O E}$ extraction from the inverse lifetime via (2) for several representative samples. It can be seen that the data is quite linear, and therefore we can be confident in the accuracy of the extracted values. $J_{O E}$ decreased somewhat in all cases after firing, indicating a slight improvement of the surface passivation. Conversely, post-firing illumination was found to have only a minor effect on $J_{O E}$. This behaviour contrasts with that of the undiffused p-type samples of Fig. 1(a) and (b), which exhibited a reduced lifetime after firing, with a substantial increase following illumination. $J_{O E}$ values of 89,42 and $28 \mathrm{fA} / \mathrm{cm}^{2}$ were measured on diffusions of 30,100 , and $210 \Omega / \square$ respectively (with active surface dopant concentrations of $\sim 2 \times 10^{19}, \sim 1.3 \times 10^{19}$, and $\sim 9 \times 10^{18} \mathrm{~cm}^{-3}$ ) after firing.

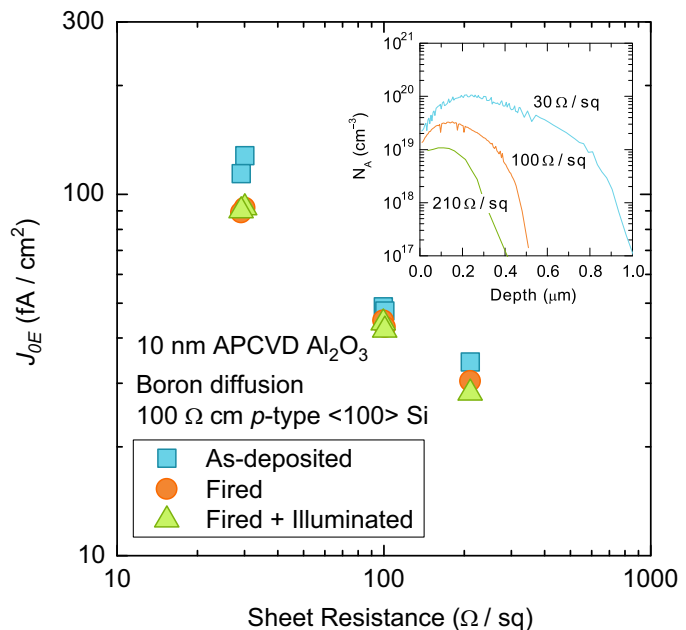

Fig. 3. Emitter saturation current density $J_{O E}$ of boron-diffused samples passivated with $\sim 10 \mathrm{~nm} \mathrm{Al}_{2} \mathrm{O}_{3}$ as a function of the sheet resistivity of the diffusion. Values are shown for the films both as-deposited, after firing with the "fast" profile, and again after illumination. The inset shows the active doping profiles of the diffusions determined by ECV measurements.

\subsection{Interface defect density and insulator charge}

To investigate the physical mechanisms behind the changes in surface passivation observed after firing, $C-V$ measurements were performed on $p$-type MIS structures with $\sim 10 \mathrm{~nm}$ thick $\mathrm{Al}_{2} \mathrm{O}_{3}$ films, both as-deposited and after firing with either the "fast" or 


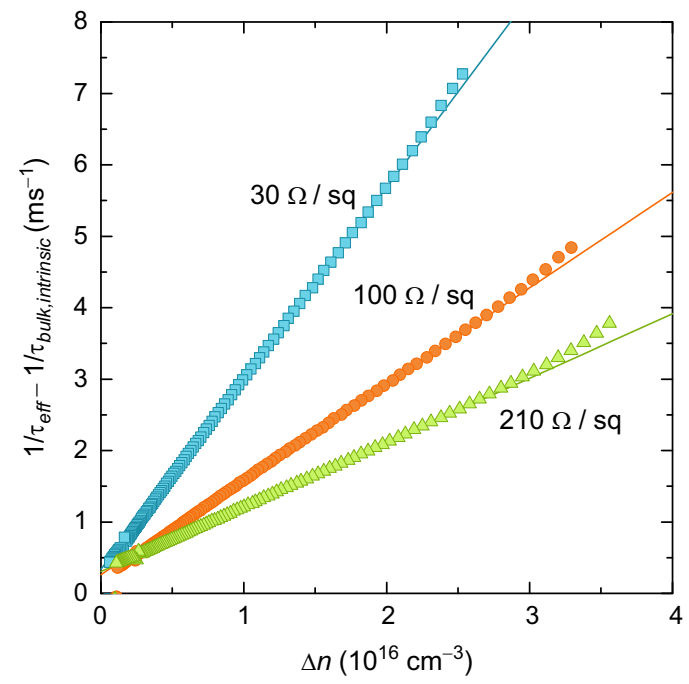

Fig. 4. Inverse effective excess minority lifetime $\tau_{\text {eff, }}$ corrected for bulk recombination, vs excess carrier density $\Delta n$ for several of the samples of Fig. 3 after illumination, showing the linear fits used to extract $J_{O E}$ via (2).

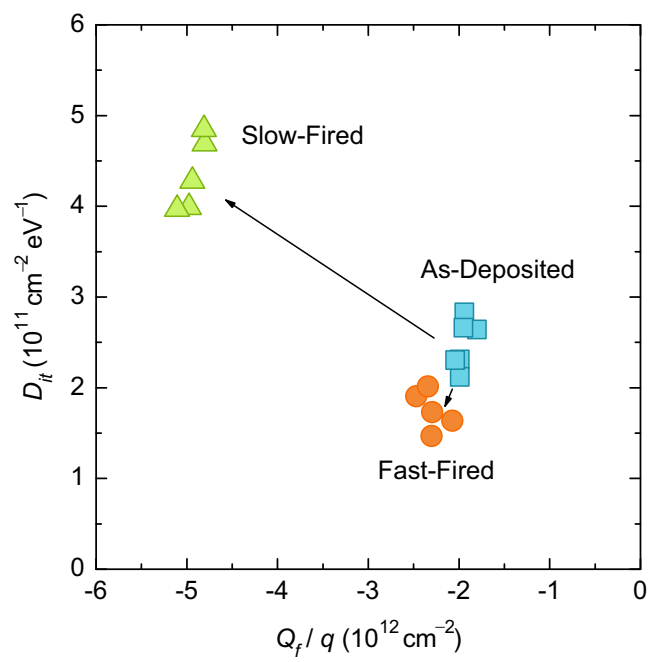

Fig. 5. Midgap interface defect density $D_{i t}$ vs insulator fixed charge density $Q_{f} / q$ for APCVD $\mathrm{Al}_{2} \mathrm{O}_{3}$ films as-deposited, and after firing with either the "fast" or "slow" firing profiles.

"slow" firing profiles. Corresponding lifetime samples were prepared on the same substrates for comparison, and fired together with the $C-V$ samples. Note that these substrates differ from those of the $p$-type samples of Fig. 1. Fig. 5 shows the midgap interface defect density $D_{i t}$ and insulator fixed charge $Q_{f}$ measured over a number of locations on each sample, while Table 1 summarises the average values, and also shows $S_{\text {eff,UL }}$ measured on the corresponding lifetime samples. Fig. 6 shows the injection-dependent lifetime data for one of the fast-fired samples.

Firing the films with the "fast" profile resulted in a reduction of the average midgap $D_{i t}$ from 2.5 to $1.75 \times 10^{11} \mathrm{~cm}^{-2} \mathrm{eV}^{-1}$, while the negative insulator fixed charge $Q_{f} / q$ increased slightly from -1.95 to $-2.3 \times 10^{12} \mathrm{~cm}^{-2}$. This is consistent with the post-firing decrease in $S_{\text {eff,UL }}$ observed for the corresponding lifetime samples (Table 1), though it contrasts with the reduction in post-firing lifetime observed for most of the samples in Fig. 1(a) prior to illumination. Firing with the "slow" profile resulted in a substantial increase in both $D_{i t}$ and $Q_{f} / q$ to average values of $4.35 \times 10^{11} \mathrm{~cm}^{-2} \mathrm{eV}^{-1}$ and $-4.9 \times 10^{12} \mathrm{~cm}^{-2}$ respectively. While the apparent measured $Q_{f}$ includes interface trapped charge $Q_{i t}$, which scales with $D_{i t}$, this is
Table 1.

\begin{tabular}{|c|c|c|c|c|}
\hline Condition & $\begin{array}{l}D_{i t} \\
\left(10^{11} \mathrm{~cm}^{-2} \mathrm{eV}^{-1}\right)\end{array}$ & $\begin{array}{l}Q_{f} / q \\
\left(10^{12} \mathrm{~cm}^{-2}\right)\end{array}$ & $\begin{array}{l}\text { Modelled } S_{\text {eff }} \\
(\mathrm{cm} / \mathrm{s})\end{array}$ & $\begin{array}{l}\text { Measured } S_{\text {eff, }} \\
u L(\mathrm{~cm} / \mathrm{s})\end{array}$ \\
\hline As-deposited & 2.5 & -2.0 & 21.9 & 17.8 \\
\hline Fast-fired & 1.8 & -2.3 & 11.7 & 12.8 \\
\hline Slow-fired & 4.4 & -4.9 & 6.4 & 15.3 \\
\hline
\end{tabular}

Average midgap $D_{i t}$ and $Q_{f}$ derived from the data of Fig. 5, compared to $S_{\text {eff,UL }}$ measured on lifetime samples fabricated on the same $1 \Omega \mathrm{cm} p$-type substrates, for $\sim 10 \mathrm{~nm}$ APCVD $\mathrm{Al}_{2} \mathrm{O}_{3}$ films as-deposited, and after firing with either the "fast" or "slow" profile. The value of $S_{\text {eff }}$ predicted from this measured $D_{i t}$ and $Q_{f}$ using the defect model of [31] is also shown.

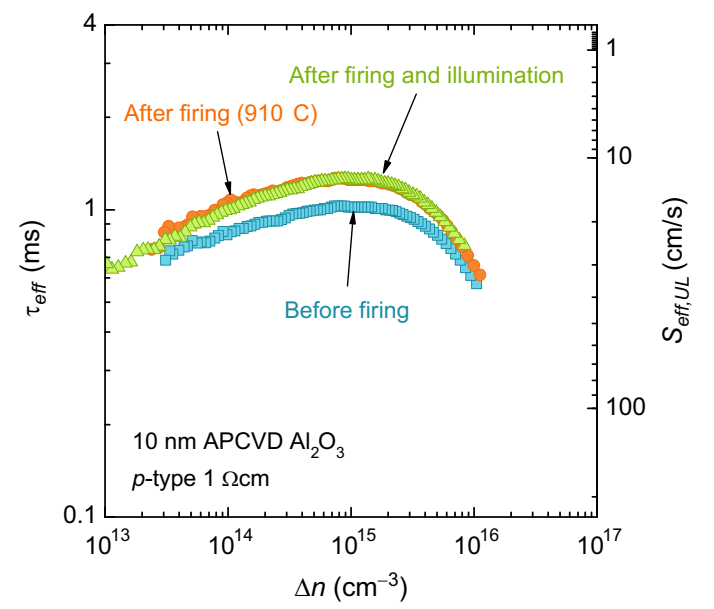

Fig. 6. Effective excess carrier lifetime $\tau_{e f f}$ as a function of excess carrier concentration $\Delta n$, both before and after firing, and after firing and illumination, for a lifetime sample fabricated on the same $1 \Omega \mathrm{cm}$-type wafers used for the $C-V$ measurements, and fired using the "fast" profile.

unlikely to be greater than $\sim 1.5 \times 10^{11} \mathrm{~cm}^{-2}$ in this case, and will almost certainly be positive, so that it cannot account for the increase in $Q_{f}$. The corresponding lifetime data show that the net result is a slight decrease in $S_{\text {eff,UL }}$ compared to the as-deposited films, with the increase in charge slightly overcompensating the increase in $D_{i t}$.

Fig. 7(a) shows example $C-V$ data for films as-deposited, and after firing with the fast and slow profiles. The increase of negative insulator fixed charge with firing can clearly be seen in the shift of the $C-V$ curves to the right. Fig. $7(\mathrm{~b})$ shows the corresponding interface defect energy distributions $D_{i t}(E)$ calculated from the same data. The shape of the distribution is virtually unchanged after both firing steps, indicating that defect passivation or depassivation during firing does not significantly alter the relative concentration of different defect species at the interface. The apparent large peak of $D_{i t}(E)$ in the upper part of the bandgap is an artefact due to non-equilibrium current flow when sweeping the gate voltage from inversion to accumulation at room temperature in these samples [31]. Its magnitude depends on temperature and sweep rate, decreasing at higher temperatures and slower sweep rates. Measurements on $n$-type samples show that the defect density is in fact fairly flat through this range.

Table 1 also shows $S_{\text {eff }}$ calculated from the average measured $D_{i t}(E)$ and $Q_{f}$ values (also Table 1) with the defect model of [32], using the method of [33] to determine the surface potential. It can be seen that there is good quantitative agreement between the modelled and measured values of the surface recombination velocity for the as-deposited and fast-fired samples, when $Q_{f} / q$ is around $-2 \times 10^{12} \mathrm{~cm}^{-2}$, but the strength of the charge-assisted passivation due to the higher charge of the slow-fired films is 


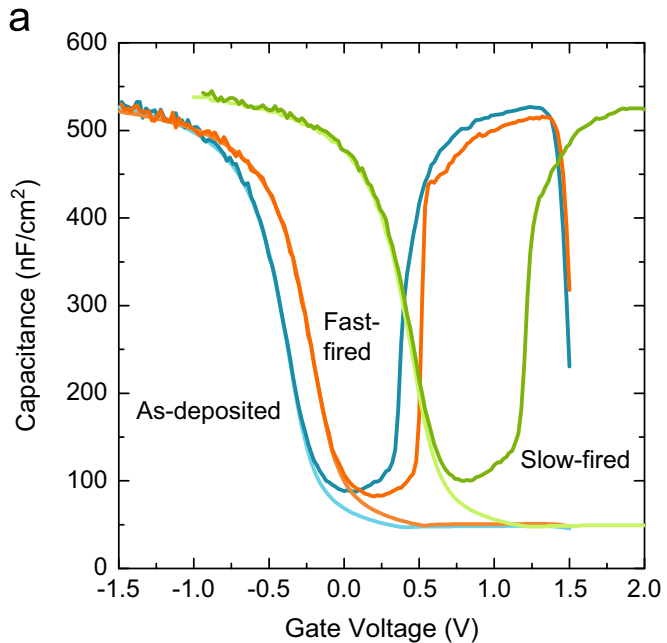

b

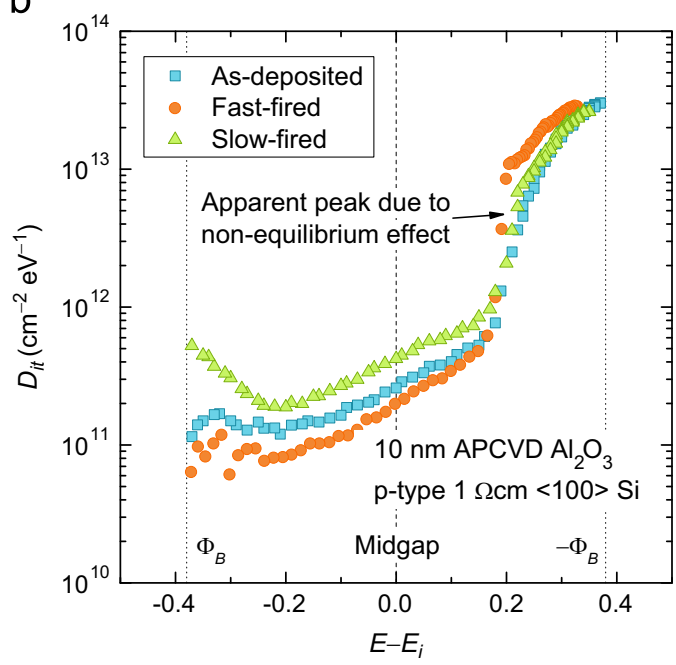

Fig. 7. a) Representative high frequency and quasi-static capacitance-voltage data, and b) corresponding interface defect density $D_{i t}(E)$ as a function of energy with respect to midgap, for $\sim 10 \mathrm{~nm} \mathrm{APCVD} \mathrm{Al}_{2} \mathrm{O}_{3}$ as-deposited, and after firing with either the "fast" and "slow" firing profiles. $D_{i t}(E)$ Values are shown for $E-E_{i}$ between $\pm \Phi_{B}$, the bulk potential, which corresponds to the thresholds of accumulation and strong inversion. $D_{i t}$ extraction is inaccurate outside of this range because of large uncertainty in the substrate capacitance. The apparent large peak in $D_{i t}(E)$ in the upper part of the bandgap is an artefact due to non-equilibrium effects.

significantly overestimated by the Boltzmann carrier statistics, consistent with the results of [32]. The higher values of $S_{\text {eff.UL }}$ for these samples compared to the $1.35 \Omega \mathrm{cm}$ samples shown in Figs. 1 and 2 are only partly explained by the difference in dopant density. The additional difference may be due to a higher $D_{i t}$ as a result of the rougher surfaces of the $1 \Omega \mathrm{cm}$ samples, or due to differences between the actual bulk lifetime of the samples and the empirical parameterisation of [22]. In neither case are our conclusions significantly affected.

\subsection{Effect of post-firing illumination on $C-V$ characteristics}

Several attempts were made to probe the previously observed illumination recovery effect via $C-V$ measurements. MIS samples were measured before and after several minutes of illumination with a halogen lamp at $50 \mathrm{~W}$ (illumination occurred with the $\sim 100 \mathrm{~nm}$ thick Al gate contacts in place, but the diffusion length in these samples should be greater than the diameter of the contacts, and the effect appears to be induced by the carrier concentration rather than the photon energy). No significant change in $D_{i t}(E)$ or $Q_{f}$ was observed after illumination. The high frequency capacitance at zero bias was also monitored prior to and immediately after the removal of illumination. If charge injection under illumination were creating additional insulator charge, the $C-V$ curves would shift along the voltage axis and the capacitance at a given gate bias would increase or decrease accordingly. However, no such change in the capacitance was observed.

The lack of response of the MIS samples to illumination is consistent with the behaviour of the lifetime samples on the same substrates. These exhibited only a very small increase in $\tau_{\text {eff }}$ after illumination, which could be entirely attributed to the presence of a small concentration of iron in the silicon bulk (from the difference in pre- and post-illumination injection-dependence of $\tau_{\text {eff }}$ ). Coupled with the similar behaviour of the boron-diffused samples with respect to firing and illumination, this suggests that the behaviour observed for the p-type samples of Fig. 1(a) and (b) might be a substrate-dependent effect, rather than an intrinsic property of the films. This is unexpected, and indeed the use of different substrates for the MIS measurements, which revealed this dependence, was based on the opposite assumption.

\subsection{Comparison to other deposition methods}

Fig. 8 compares post-firing lifetimes as a function of film thickness for $\mathrm{Al}_{2} \mathrm{O}_{3}$ single layers and $\mathrm{Al}_{2} \mathrm{O}_{3} / \mathrm{SiN}_{x}$ stacks deposited by several different methods, including PA-ALD and inductively coupled plasma (ICP) PECVD [16], as well as the APCVD results reported here. Error bars show the standard deviation of measurements for multiple samples. The comparison is direct because both the substrates and the firing conditions are identical. It can be seen that the APCVD films perform well relative to those deposited by other techniques, with generally higher lifetimes than for the ICP PECVD films, at least after illumination, and not far below the state-of-the-art PA-ALD films, which in any case are not suitable for high throughput applications because of their low deposition rate. All of the films provide a level of surface passivation sufficiently high that it would not limit the efficiency of a typical industrial high-efficiency cell [34].

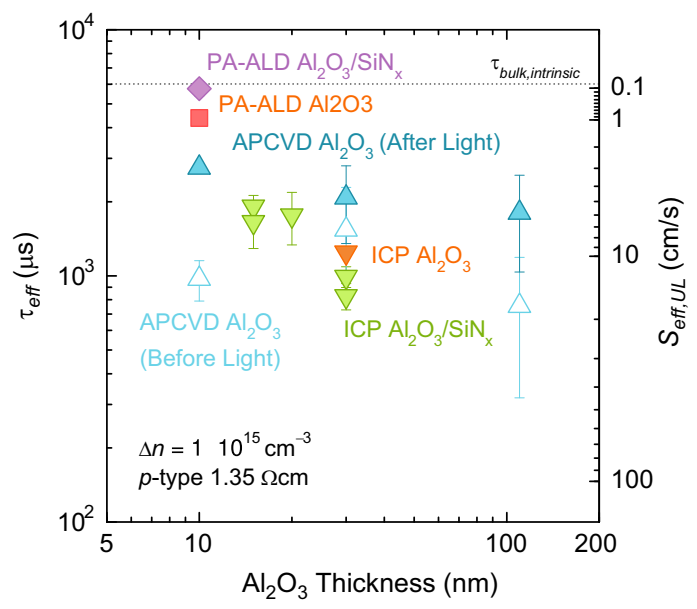

Fig. 8. Comparison of post-firing lifetimes for $\mathrm{Al}_{2} \mathrm{O}_{3}$ films and $\mathrm{Al}_{2} \mathrm{O}_{3} / \mathrm{SiN}_{x}$ stacks deposited by various methods. All samples were fabricated on the same $300 \mu \mathrm{m}$ thick, $1.35 \Omega \mathrm{cm}$ p-type samples, and fired with the same "fast" firing profile. Data points show average values and error bars the standard deviation derived from multiple samples. The intrinsic bulk lifetime according to the parameterisation of [22] is indicated by the dotted line. Data for the PA-ALD and inductively coupled plasma (ICP) PECVD samples are from [16]. 


\section{Conclusion}

$\mathrm{Al}_{2} \mathrm{O}_{3}$ films deposited by APCVD have been shown to provide excellent, stable surface passivation under a typical hightemperature fast-firing step, as used in the metallisation of screen-printed silicon solar cells. Passivation generally showed minor changes for $n$-type samples and improved for $p$-type samples and boron-diffused planar samples following firing and illumination. Final lifetimes were generally sufficiently high that they would not limit solar cell efficiency. Initial degradation after firing and recovery under illumination was observed for some p-type substrates, but not others, suggesting a substrate dependence of the effect. No systematic dependence on the $\mathrm{Al}_{2} \mathrm{O}_{3}$ film thickness, or on the presence or absence of a $\operatorname{SiN}_{x}$ capping layer, was observed. $C-V$ measurements showed that short firing times resulted in an initial reduction of interface defect density $D_{i t}$ and a small increase in insulator charge $Q_{f}$, while longer firing times led to substantial increases in both $D_{i t}$ and $Q_{f}$. These results demonstrate the suitability of APCVD $\mathrm{Al}_{2} \mathrm{O}_{3}$ for integration into devices undergoing rapid high-temperature thermal processing.

\section{References}

[1] B. Hoex, S.B.S. Heil, E. Langereis, M.C.M. van de Sanden, W.M.M. Kessels, Ultralow surface recombination of $\mathrm{c}$-Si substrates passivated by plasmaassisted atomic layer deposited $\mathrm{Al}_{2} \mathrm{O}_{3}$, Applied Physics Letters 89 (2006) 042112-1-042112-3.

[2] G. Agostinelli, A. Delabie, P. Vitanov, Z. Alexieva, H.F.W. Dekkers, S. De Wolf, G. Beaucarne, Very low surface recombination velocities on $p$-type silicon wafers passivated with a dielectric with fixed negative charge, Solar Energy Materials and Solar Cells 90 (2006) 3438-3443.

[3] P. Poodt, A. Lankhorst, F. Roozeboom, K. Spee, D. Maas, A. Vermeer, High-speed spatial atomic-layer deposition of aluminum oxide layers for solar cell passivation, Advanced Materials 22 (2010) 3564-3567.

[4] B. Vermang, A. Rothschild, A. Racz, J. John, J. Poortmans, R. Mertens, P. Poodt V. Tiba, F. Roozeboom, Spatially separated atomic layer deposition of $\mathrm{Al}_{2} \mathrm{O}_{3}$, a new option for high-throughput Si solar cell passivation, Progress in Photovoltaics: Research and Applications 19 (2011) 733-739.

[5] P. Saint-Cast, D. Kania, M. Hofmann, J. Benick, J. Rentsch, R. Preu, Very low surface recombination velocity on $p$-type $c$-Si by high-rate plasma-deposited aluminum oxide, Applied Physics Letters 95 (2009) 151502-1-151502-3.

[6] S. Miyajima, J. Irikawa, A. Yamada, M. Konagai, High quality aluminum oxide passivation layer for crystalline silicon solar cells deposited by parallel-plate plasma-enhanced chemical vapor deposition, Applied Physics Express 3 (2010) 012301-1-012301-3.

[7] R. Hezel, K. Jaeger, Low-temperature surface passivation of silicon for solar cells, Journal of the Electrochemical Society 136 (1989) 518-523.

[8] L.E. Black, K.R. McIntosh, Surface passivation of $c$-Si by atmospheric pressure chemical vapour deposition of $\mathrm{Al}_{2} \mathrm{O}_{3}$, Applied Physics Letters 100 (2012) 202107-1-202107-5.

[9] T.T. Li, A. Cuevas, Effective surface passivation of crystalline silicon by rf sputtered aluminum oxide, Physica Status Solidi 3 (2009) 160-162.

[10] X. Zhang, A. Cuevas, A. Thomson, Process control of reactive sputter deposition of $\mathrm{AlO}_{x}$ and improved surface passivation of crystalline silicon, IEEE Journal of Photovoltaics 3 (2013) 183-188.

[11] J. Benick, A. Richter, M. Hermle, S.W. Glunz, Thermal stability of the $\mathrm{Al}_{2} \mathrm{O}_{3}$ passivation on p-type silicon surfaces for solar cell applications, Physica Status Solidi (RRL) 3 (2009) 233-235.

[12] B. Vermang, X. Loozen, C. Allebé, J. John, E. van Kerschaver, J. Poortmans, and R. Mertens, Characterization and implementation of thermal ALD $\mathrm{Al}_{2} \mathrm{O}_{3}$ as surface passivation for industrial Si solar cells, in: Proceedings of the 24th European Photovoltaic Solar Energy Conference, Hamburg, Germany, 2009, pp. 1051-1054.

[13] J. Schmidt, B. Veith, R. Brendel, Effective surface passivation of crystalline silicon using ultrathin $\mathrm{Al}_{2} \mathrm{O}_{3}$ films and $\mathrm{Al}_{2} \mathrm{O}_{3} / \mathrm{SiN}_{x}$ stacks, Physica Status Solidi (RRL) 3 (2009) 287-289.
[14] B. Veith, F. Werner, D. Zielke, R. Brendel, J. Schmidt, Comparison of the thermal stability of single $\mathrm{Al}_{2} \mathrm{O}_{3}$ layers and $\mathrm{Al}_{2} \mathrm{O}_{3} / \mathrm{SiN}_{x}$ stacks for the surface passivation of silicon, Energy Procedia 8 (2011) 307-312.

[15] G. Dingemans, P. Engelhart, R. Seguin, F. Einsele, B. Hoex, M.C.M. van de Sanden, W.M.M. Kessels, Stability of $\mathrm{Al}_{2} \mathrm{O}_{3}$ and $\mathrm{Al}_{2} \mathrm{O}_{3} / \mathrm{a}-\mathrm{SiN}_{\mathrm{x}}: \mathrm{H}$ stacks for surface passivation of crystalline silicon, Journal of Applied Physics 106 (2009) 114907-1-114907-4

[16] B. Veith, T. Dullweber, M. Siebert, C. Kranz, F. Werner, N.-P. Harder, J. Schmidt, B.F.P. Roos, T. Dippell, R. Brendel, Comparison of ICP-AlO $\mathrm{A}_{x}$ and $\mathrm{ALD}-\mathrm{Al}_{2} \mathrm{O}_{3}$ layers for the rear surface passivation of $c$-Si solar cells, Energy Procedia 27 (2012) 379-384.

[17] A. Richter, S. Henneck, J. Benick, M. Hörteis, M. Hermle, and S.W. Glunz, Firing stable $\mathrm{Al}_{2} \mathrm{O}_{3} / \mathrm{SiN}_{x}$ layer stack passivation for the front side boron emitter of $n$-type silicon solar cells, in: P roceedings of the 25th European Photovoltaic Solar Energy Conference, Valencia, Spain, 2010, pp. 1453-1459.

[18] B. Vermang H. Goverde, A. Lorenz, A. Uruena, G. Vereecke, J. Meersschaut, E. Cornagliotti, A. Rothschild, J. John, J. Poortmans, and R. Mertens, On the blistering of atomic layer deposited $\mathrm{Al}_{2} \mathrm{O}_{3}$ as $\mathrm{Si}$ surface passivation, in: Proceedings of the 37th IEEE Photovoltaic Specialists Conference, Seattle, USA, 2011, pp. 3562-3567.

[19] B. Vermang, H. Goverde, A. Lorenz, A. Uruena, J. Das, P. Choulat, E. Cornagliotti, A. Rothschild, J. John, J. Poortmans, and R. Mertens, On the blistering of $\mathrm{Al}_{2} \mathrm{O}_{3}$ passivation layers for $\mathrm{Si}$ solar cells, in: Proceedings of the 26th European Photovoltaic Solar Energy Conference, Hamburg, Germany, 2011, pp. 1129-1131.

[20] L. Hennen, E.H.A. Granneman, and W.M.M. Kessels, Analysis of blister formation in spatial $\mathrm{ALD} \mathrm{Al}_{2} \mathrm{O}_{3}$ for silicon surface passivation, in: Proceedings of the 38th IEEE Photovoltaic Specialists Conference, Austin, USA, 2012, pp. 10491054 .

[21] L.E. Black, K.M. Provancha, and K.R. McIntosh, "Surface passivation of crystalline silicon by APCVD aluminium oxide", in: Proceedings of the 26th European Photovoltaic Solar Energy Conference, Hamburg, Germany, 2011, pp. 11201124.

[22] A. Richter, S.W. Glunz, F. Werner, J. Schmidt, A. Cuevas, Improved quantitative description of Auger recombination in crystalline silicon, Physical Review B 86 (2012) 165202-1-165202-14

[23] J. Brody, A. Rohatgi, and A. Ristow, Guidelines for more accurate determination and interpretation of effective lifetime from measured quasi-steady-state photoconductance, in: Proceedings of the 11th Workshop on Crystalline Silicon Solar Cell Materials and Processes, Estes Park, Colorado, August 1922 2001, pp. 163-167.

[24] K. Misiakos, D. Tsamakis, Accurate measurements of the silicon intrinsic carrier density from 78 to $340 \mathrm{~K}$, Journal of Applied Physics 74 (1993) 3293-3297.

[25] G. Ghibaudo, S. Bruyère, T. Devoivre, B. DeSalvo, E. Vincent, Improved method for the oxide thickness extraction in MOS structures with ultrathin gate dielectrics, IEEE Transactions on Semiconductor Manufacturing 13 (2000) 152-158.

[26] E.H. Nicollian, J.R. Brews, MOS (Metal Oxide Semiconductor) Physics and Technology, John Wiley \& Sons, New York, 1982.

[27] C.N. Berglund, Surface states at steam-grown silicon-silicon dioxide interfaces, IEEE Transactions on Electron Devices 13 (1966) 701-705.

[28] B. Veith, T. Ohrdes, F. Werner, R. Brendel, P.P. Altermatt, N.-P. Harder, J. Schmidt, Injection dependence of the effective lifetime of $n$-type $\mathrm{Si}$ passivated by $\mathrm{Al}_{2} \mathrm{O}_{3}$ : an edge effect? Solar Energy Materials and Solar Cells (2013)

[29] S. Joos, A. Herguth, U. Hess, J. Ebser, S. Seren, B. Terheiden, G. Hahn, Light induced curing (LIC) of passivation layers deposited on native silicon oxide, Energy Procedia 27 (2012) 349-354.

[30] D. MacDonald, J. Tan, T. Trupke, Imaging interstitial iron concentrations in boron-doped crystalline silicon using photoluminescence, Journal of Applied Physics 103 (2008) 073710-1-073710-7.

[31] M. Kuhn and E.H. Nicollian, Nonequilibrium effects in quasi-static MOS measurements, 118, 1971, 370-373.

[32] L.E. Black, K.R. McIntosh, Modeling recombination at the $\mathrm{Si}-\mathrm{Al}_{2} \mathrm{O}_{3}$ interface, IEEE Journal of Photovoltaics (2013), http://dx.doi.org/10.1109/JPHOTOV.2013.2247464, in press.

[33] R.B.M. Girisch, R.P. Mertens, R.F. De Keersmaecker, Determination of $\mathrm{Si}_{-} \mathrm{SiO}_{2}$ interface recombination parameters using a gate-controlled point-junction diode under illumination,, IEEE Transactions on Electron Devices 35 (1988) 203-222.

[34] L.E. Black, T. Allen, and K.R. McIntosh, Safe and inexpensive $\mathrm{Al}_{2} \mathrm{O}_{3}$ deposited by APCVD with single-source precursor, in: Proceedings of the 28th European Photovoltaic Solar Energy Conference, Paris, France, 2013, in press. 